\title{
Mulheres no futebol: uma análise midiática pela perspectiva dos estudos culturais
}

\section{Mujeres en el fútbol: um análisis mediático desde la perspectiva de los estudios culturales}

\section{Women in soccer: a media analysis from the perspective of cultural studies}

\author{
iD Andressa Araujo Furquim \\ Instituição/Afiliação: FEFISO, Sorocaba, São Paulo, Brasil \\ E-mail: andressaa.furquim@gmail.com \\ iD (9) Maísa Ferreira \\ Instituição/Afiliação: Universidade Estadual de Campinas, Campinas, São Paulo, Brasil \\ E-mail: maisaf93@gmail.com \\ iD Nara Romero Montenegro \\ Instituição/Afiliação: Universidade Estadual de Campinas, Campinas, São Paulo, Brasil
} E-mail: nararomerom@hotmail.com

iD Rubens Antonio Gurgel Vieira

Instituição/Afiliação: FEFISO, Sorocaba, São Paulo, Brasil

E-mail: rubensgurgel@hotmail.com

\begin{abstract}
Resumo: Este artigo objetiva identificar as representações das identidades de mulheres praticantes de futebol profissional a partir de comentários em site esportivo. Articulamos os discursos midiáticos às relações de poder e, por meio da análise cultural, identificamos limitações de gênero na área da Educação Física. Os principais pontos analisados apontam as várias ofensas sofridas pelas mulheres, entre elas os imperativos da feminilidade, fragilidade, maternidade e ataques em relação à orientação sexual. Conclui-se que esses espaços colaboram na construção do que é ser mulher dentro da cultura e buscam normalizar um ideal desejado,
\end{abstract}


que confronta a conquista de visibilidade e aceitação das mulheres praticantes de futebol.

Palavras-chave: Futebol de Mulheres. Esporte. Estudos Culturais. Futebol Feminino.

Resumem: Este artículo tiene como objetivo identificar las representaciones de las identidades de las mujeres practicantes del fútbol profesional, basándose en los comentarios de un sitio web deportivo. Articulamos los discursos mediáticos con las relaciones de poder y, a través del análisis cultural, identificar las limitaciones de género en el ámbito de la Educación Física. Los principales puntos analizados apuntan a los diversos delitos que sufren las mujeres, entre ellos los imperativos de feminidad, fragilidad, maternidad y agresiones en relación con la orientación sexual. Se concluye que estos espacios colaboran en la construcción de lo que significa ser mujer dentro de la cultura y buscan normalizar un ideal deseado, que enfrente el logro de visibilidad y aceptación de las futbolistas.

Palabras clave: Fútbol de mujeres; Deporte; Estudios Culturales; Fútbol feminino.

Abstract: This article aims to identify the representations of the identities of women in professional soccer, based on comments on a sport website. We attempt to articulate media discourses with power relations and, through cultural analysis, identify gender limitations in the area of Physical Education. The main points analyzed indicate to the various offenses suffered by women, among them the imperatives of femininity, fragility, motherhood and attacks in relation to sexual orientation. It is concluded that these spaces collaborate in the construction of what it means to be a woman within the culture and seek to normalize a desired ideal, which confronts the achievement of visibility and acceptance of women who play football.

Keywords: Women's soccer; Sport; Cultural Studies; Women's World Cup.

Submetido em: 15-04-2021

Aceito em: 14-05-2021 


\section{Introdução}

Com a globalização no final do século XX, o campo dos Estudos Culturais (EC) foi um dos responsáveis por quebrar diversas barreiras disciplinares ao analisar uma mesma situação problema. Segundo a autora Escosteguy (1998), a intencionalidade do foco desse quadro teórico é a preocupação com as demandas sociais, trabalhando com diversas matrizes do conhecimento para observar a cultura popular e os movimentos sociais.

Hall (2003) discute sobre a necessidade de teorizar sobre eventos históricos concretos e sintomáticos, estabelecendo uma relação entre o micro e o macro - o que se torna um dos princípios que move nossa pesquisa. Assim, a cultura deixa de possuir somente o papel de ramificação nas análises da sociedade, mas toma para si o protagonismo e se torna a principal ferramenta de análise (HALL, 2003).

A partir desses pressupostos, entendemos a cultura como campo de disputa por significados, no caso do presente estudo, a luta pela significação dos corpos das mulheres dentro da prática do futebol. Tal ação produz representações das práticas culturais e, concomitantemente, regulamenta identidades de acordo com relações de poder específicas, contextuais e contingentes, pois, conforme afirma Hall (2016, p. 31), "a representação conecta o sentido e a linguagem à cultura". Cabe destacar que a representação aqui não é evocada no sentido tradicionalmente alocado no campo da psicologia, enquanto uma abstração mental, mas sim de substratos materiais que são significados nas relações humanas.

Foi com esse quadro teórico que passamos a observar as regulações culturais que agem sobre a representação da identidade das mulheres no âmbito esportivo, mais especificamente no futebol de campo. O referencial foi escolhido pelo seu potencial em questionar identidades naturalizadas e pela sua herança tradicional de lutas pelas culturas marginalizadas, pela voz da diferença - nesse caso, a identidade das jogadoras brasileiras. 
De início, vale ressaltar a grande dificuldade de acesso das mulheres ao futebol. Segundo Moraes e Bonfim (2016) e Goellner (2005), as desigualdades sociais, os estereótipos e as ofensas sofridas pelas mulheres são intensas e limitam a participação nos espaços esportivos. Contudo, acreditamos que a trama é mais complexa do que somente a possibilidade de acesso. Sabe-se que existem barreiras socioculturais impostas às mulheres de acordo com tendências conservadoras que configuram as formas de ser, agir e pensar das/nas mesmas. Trata-se, portanto, de uma questão de identidade, cultura e gênero, ou seja, dimensões de uma estrutura esportiva que alija as mulheres de seu centro, relegando sua participação ao papel coadjuvante, quando muito.

Especificamente dentro do fenômeno futebol, as mulheres são julgadas com mais intensidade, como afirma Ferreira et al. (2018, p. 126) "[...] um dos fatores principais que contribuem para que esse preconceito fique alojado é a nossa própria sociedade que criou seu padrão e modo de visão em relação às mulheres". Dessa forma, dentre múltiplos aspectos possíveis de serem levantados, o fato das mulheres apresentarem "salários menores, menor visibilidade por parte da imprensa, campeonatos com menos apelação midiática" (FERREIRA et al., 2018, p. 120) pode resultar em desmotivação da prática do futebol pelas mulheres.

Os autores supracitados enfatizam ainda sobre o cenário na competição brasileira feminina, apontando a mídia como veículo de fala que fortalece a desvalorização das mulheres no esporte, em razão da falta de representatividade, que enaltece o mito de fragilidade do sexo feminino, prejudicando, assim, as conquistas no mercado e os direitos das jogadoras (FERREIRA et al., 2018). Portanto, para analisar os julgamentos da população de mulheres e seus reflexos sintomáticos, que são frutos das relações de poder da sociedade, os meios de comunicação se tornam uma peça chave de compreensão e articulação com o real.

Temos então as peças conceituais que delimitam nosso estudo: a regulamentação identitária via circuito da cultura, a identidade mulher jogadora, o esporte moderno (com ênfase no futebol) 
e o funcionamento midiático. A partir do entrecruzamento desses aspectos, é possível traçar mapas culturais da posição subalternizada da mulher com o intuito de desconstruir discursos e proporcionar a circulação de novos enunciados, mais libertários e justos. Diante disso, anunciamos que o objetivo dessa exploração é questionar algumas representações de mulheres que jogam futebol profissional a partir do campo midiático. Para tanto, adotamos como metodologia a análise cultural, tendo como dados os comentários dos usuários nas mídias esportivas alocadas em sítios virtuais. A partir desse recorte analítico, buscamos compreender como a presença das mulheres no futebol é representada na sociedade contemporânea e colabora na produção identitária, regulando a subjetividade daqueles que fazem a leitura dos conteúdos.

\section{Procedimentos metodológicos}

Para Hall (2016), o local onde se desenrola a forja identitária é o campo cultural, povoado por vetores de força que lutam por hegemonia, combinações que terminam por produzir representações das práticas culturais e regulamentar as identidades de acordo com certas relações de poder sempre específicas, contextuais e contingentes: "a representação conecta o sentido e a linguagem à cultura" (p. 31). Assim, para entender como as disputas culturais acontecem, um dos passos necessários passa por estudar como as representações são criadas e colocadas para circular.

Ainda com Hall (1997), o conceito de cultura pode ser analisado de duas maneiras distintas: a primeira forma é substantivamente, uma "estrutura empírica real", que discorre sobre a organização corriqueira diária de instituições e outros aspectos da sociedade em uma situação histórica selecionada. A segunda via é epistemológica, se referindo à influência da cultura nas questões de contextos e "em como a cultura é usada para transformar nossa compreensão, explicação e modelos teóricos do mundo" (HALL, 
1997, p. 16). Entende-se que, tanto na visão substantiva quanto na epistemológica, a cultura adquiriu importância na questão de análise das situações da sociedade de forma global - a chamada centralidade da cultura. Todavia, dadas as limitações de escopo da pesquisa e espaço, nos limitaremos aos seus aspectos epistemológicos, ou seja, nos confrontos discursivos.

As representações funcionam como um modo de atribuir significados, ou seja, como uma forma comunicativa, e como tal estão assujeitadas às normas da linguagem na concepção contemporânea: culturais, arbitrárias e indeterminadas. No campo dos EC, as práticas que produzem significados são envoltas por relações de poder que definem o que é a regra (identidade) e o que será excluído (diferença). Os sistemas representativos servem justamente para classificar de forma hierárquica o que é a norma cultural, sempre emitindo padrões a partir de julgamentos de conduta. $O$ primeiro passo, portanto, é reconhecer que investigar a cultura é analisar contextualmente os sistemas de representação que the configuram, atentando para as relações de poder que Ihe moldam.

Para Woodward (2008), de forma estrita, cultura é justamente a somatória dos sistemas classificatórios que tencionam a criação de uma ordem a partir de fronteiras delimitativas. Para a compreensão de uma identidade se faz necessário, assim, analisar sistemas representativos das identidades, buscando a compreensão da sua produção, consumo e regulação dentro do chamado circuito da cultura. Como um circuito, a trajetória analítica não é linear, pois cada seção do circuito está intrinsecamente conectada à outra e a demarcação serve, unicamente, para o enfoque nos diversos momentos. No caso específico deste trabalho, o enfoque na identidade mulher jogadora de futebol de campo.

O objeto demarcado, por sua vez, é compreendido como um artefato cultural, ou seja, como a combinação de processos constitutivos da cultura via sistemas simbólicos representativos. O objetivo é demonstrar os rastros inventivos no seu processo de naturalização. Coiro-Moraes (2016) afirma o comprometimento da análise cultural com as mazelas sociais que aparecem com as prá- 
ticas da sociedade selecionada como estudo de caso. Assim, no método analítico da cultura objetiva-se atingir questões sintomáticas de comunidade e oferecer algumas respostas a essas mazelas, articulando entre macro e micro em um grupo específico e em dado lugar. Como caráter dos EC, esse procedimento é uma construção teórica que não recorre à definição, entretanto, se vincula com questões políticas e se articula com a produção e o consumo cultural.

Novamente com Hall (1997), o autor afirma que os trabalhos dos EC no campo da comunicação problematizam as produções de sentidos midiáticas, investigando os programas televisionados, transmitidos via rádio, textos da internet ou outros meios, sempre observando que são fartos de significados produzidos no circuito. Constatam, também, que a "significação torna-se objeto de investida por parte da ideologia dominante na tentativa de propor um sentido preferencial, articulado com os seus interesses" (ROCHA, 2011, p. 06).

Logo, existe uma trama complexa midiática que argumenta e elabora conteúdo com propósito, um processo que necessita de questionamento. De acordo com Rocha (2011), os EC questionam a mídia ao analisar a partir da abordagem cultural e fortalecem o estudo político teórico.

Para as pesquisas em comunicação, a articulação comum aos circuitos da cultura é, sobretudo, uma forma de apresentar as relações entre a esfera produtiva e suas representações midiáticas e as maneiras pelas quais os sujeitos se apropriam das mensagens, como as decodificam e delas fazem uso em suas vidas privadas (COIRO-MORAES, 2016, p. 34).

Assim, as análises de um texto midiático buscam interpretar a comunicação presente nos códigos que são os resultados da ligação entre produtores de conteúdo e consumidores. O objetivo é reconhecer o arranjo de cruzamentos de informações que operam com as relações de poder (COIRO-MORAES, 2016). Ao identificar as 
relações de poder das práticas sociais pelos signos que se apresentam, ou seja, nos padrões que se repetem e nos detalhes que escapam, uma investigação cultural abre espaço para a circulação de outros discursos, o que eventualmente pode produzir outras formas de ser, pensar e agir. No caso, se permite a diferença.

Buscando articular a construção da identidade mulher no esporte em seus aspectos macro e micro, esta pesquisa selecionou o grupo cultural de mulheres que jogam futebol na seleção brasileira. Diante do exposto e seguindo tais premissas, durante o mês de maio de 2020, através do site globoesporte.globo.com, foram realizadas buscas na página entre os dias 7 de junho a 7 de julho do ano de 2019. O período remetia à duração da 8 a Copa do Mundo de Futebol Feminino da Fifa realizada na França. Utilizamos na busca as seguintes palavras-chave: Copa do Mundo de Futebol Feminino.

Foram encontradas quatro matérias no período, as quais por sua vez, compuseram o escopo de análise inicial, com enfoque nos comentários dos usuários. Por conseguinte, a pesquisa iniciou com a premissa de compreender os vetores de força através de uma rede de informações sobre esportes. Com o andar das investigações, percebemos que apenas uma matéria bastava em termos de material empírico, uma vez que nas seguintes o que se dava era uma repetição discursiva.

Entretanto, com o decorrer da escrita, realizamos uma mudança de foco na investigação dos textos de notícia para os comentários. Tal operação foi feita por entendermos que os comentários estão mais livres de amarras legais, mercadológicas e esportivas, e também operam dentro do circuito da cultura, funcionando, portanto, como reflexos de certas representações hegemônicas que possuem mais poder na disputa por significados. Nas indicações legais do sítio virtual escolhido como base, os comentários são descritos como responsabilidade exclusiva de seus autores. Como forma de evitar implicações éticas negativas, os autores dos comentários foram colocados no anonimato e organizados gramaticalmente para melhor entendimento. 
Ao todo foram analisados 71 comentários, retirados do espaço aberto ao público, local em que as pessoas exercem o direito de se posicionar, quase sempre gerando uma discussão pelo poder de representar. Destes comentários escolhidos, nove ganharam destaque nas análises pelo impacto dos seus códigos. Os comentários selecionados, então, foram submetidos à análise cultural e nossas considerações vêm na sequência.

\section{Mulheresnofutebol:questionandomitosdafeminilidade, fragilidade, maternidade e sexualidade}

No mundo globalizado, o circuito da cultura desenvolve um ritmo acelerado acarretando identidades híbridas, sujeitos que passam pelo processo de desprendimento do seu lugar dito como fixo, ocorrendo uma fragmentação em todo sistema em rede, um processo de regulamentação em escala global (HALL, 2006). Para Hall $(2006$, p. 71), “o tempo e o espaço são também as coordenadas básicas de todo sistema de representação" e o resultado da globalização é uma compressão espaço-tempo que afeta todo o processo identitário. Esse fenômeno pode ser bem visualizado no comportamento humano nas redes sociais, em que os espaços destinados aos comentários servem bem como amostragem.

A globalização trouxe em sua esteira mudanças temporais e tecnológicas que tornaram o processo de identificação mais provisório, variável e problemático. Assim, a identidade antes fixada de maneira mais estável, muitas vezes sendo compreendida de forma essencial ou permanente, atualmente se apresenta como muito mais instável, falha e vacilante. Logo, as manifestações culturais do indivíduo são fragmentadas e complexas, o que pode apresentar uma oportunidade histórica de rompimento com fronteiras limitantes - no caso que nos interessa, a posição das mulheres no futebol brasileiro. Não obstante, tais transformações não ocorrem sem resistência, ou seja, apesar de todo processo de mudança, há 
Mulheres no futebol: uma análise midiática pela perspectiva dos estudos culturais Andressa Araujo Furquim • Maísa Ferreira • Nara Romero Montenegro • Rubens Antonio Gurgel Vieira

alguns comportamentos que ainda são defendidos, bases sólidas do passado: "As identidades nacionais e outras identidades locais ou particulares estão sendo reforçadas pela resistência à globalização" (HALL, 2006, p. 69). Entendemos que se encaixam nessa categoria as identidades reacionárias, apegadas às estruturas limitantes do passado que insistem em manter as mulheres em posições subalternas.

Vejamos o exemplo da reportagem analisada que se intitula Qual é, qual é... futebol não é pra mulher?: conheça a história por trás do hino da Seleção na Copa'. O texto trata do período inicial da competição e considera que, à medida que os jogos foram acontecendo, a torcida brasileira gradativamente alimentou esperanças em obter bons resultados na competição com a seleção. Na partida de estreia, a atacante Cristiane marcou três gols contra a seleção da Jamaica e, seguindo uma tradição do futebol brasileiro², escolheu para comemorar o seu feito a música Jogadeira. Composta pela jogadora, então do Corinthians, Cacau, com a ex-jogadora Gabi Kivitz, a canção aborda os preconceitos enfrentados pelas jogadoras desde a infância e reivindica a prática do futebol como pertencente também às mulheres, tendo como refrão a pergunta irônica: "Qual é/ qual é/ futebol não é para mulher?", e que conclui com uma resposta desafiadora usando o vocativo masculino mané: "Eu vou mostrar pra você, mané/ Joga a bola no meu pé". O que Cristiane, entretanto, não previu foram os efeitos sobre o grupo da seleção feminina e a repercussão de sua escolha.

Tomamos esse ponto para análise, pois os efeitos, além de intensos, foram diversos. Vários discursos manifestaram apoio e alegria com a presença das mulheres na mídia esportiva, mas muitos também apresentaram críticas e uma série de preconceitos conforme veremos nos comentários selecionados.

\footnotetext{
1 KESTELMAN, Amanda; BASTOS, Denise Thomaz. "Qual é, qual é... futebol não é pra mulher?": conheça a história por trás do hino da Seleção na Copa. França: 2019. Disponível em: https://globoesporte.globo.com/futebol/copa-do-mundo-feminina/ noticia/qual-e-qual-e-futebol-nao-e-pra-mulher-conheca-a-historia-por-tras-do-hino-da-selecao-na-copa.ghtml. Acesso em: 15 mai. 2020

2 No futebol brasileiro existe uma dinâmica do jogador ou jogadora ter direito a pedir uma música quando faz três gols ou mais em uma partida. Essa dinâmica se iniciou com o programa Fantástico da Rede Globo e se difundiu em diversos contextos do futebol.
} 
Não é preconceito, mas muitas são muito MASCULINIZADAS, a diferença nesse quesito é clara entre as mulheres do vôlei e as do futebol!!! Nada contra, mas é estranho (Comentário 1: disponível em GLOBO ESPORTE, 2019, KESTELMAN, BASTOS, 2019).

Embora o usuário negue uma posição de preconceito, ele parte de uma concepção essencialista de ser mulher, ou seja, uma representação de que há uma natureza feminina e ela é necessariamente não masculinizada. Por que os corpos das mulheres não podem ser musculosos? O comentário que posiciona os corpos das mulheres masculinizados como algo estranho, fora de uma suposta normalidade, sintetiza o argumento de "marcas biológicas" (LOURO, 2000 p. 8). Além disso, o destaque dado aos corpos das jogadoras e sua categorização como masculinizados enfatiza a beleza em detrimento da qualidade técnica, tática e física, ou seja, a performance atlética é totalmente secundarizada quando confrontada com uma imagem corporal idealizada esteticamente. É a crença de que a feminilidade é característica intrínseca às mulheres.

Esse é o processo de significar as características individuais e, mediante certos detalhes, dizer qual corpo pode existir e qual deve ser negado. Tratando-se de um esporte profissional, demanda-se que as atletas sejam treinadas para esse nível, por isso, seus corpos corresponderam a estímulos de forma expressiva, com altos níveis de treinamento, resultando em músculos definidos e fortes.

Entretanto, de acordo com visões essencialistas historicamente construídas, o corpo forte, rígido e musculoso é caracterizado como masculino e, por outro lado, o corpo feminino é representado como aquele delicado, frágil, maternal e frequentemente hipersensualizado, sobretudo na juventude (GOELNNER, 2003). Se analisarmos a prática esportiva do futebol, são as mesmas regras que valem para ambas as modalidades, masculino e feminino são regidos pela mesma Federação Internacional de Futebol, possuem uniformes e acessórios semelhantes, bem como o mesmo objetivo esportivo, isto é, fazer gols. Obviamente que são jogos com 
características diferentes, com dinâmicas e suas particularidades específicas, porém a lógica esportiva é a mesma, o que os difere, portanto, é a posição de sujeitos praticantes como supostamente mais ou menos legítimos. Ao mesmo tempo, fomenta-se a regulação dos corpos, produzindo uma identidade única de mulher que, nesse caso, deve praticar o esporte com determinado corpo.

Em seguida, outro comentário sustenta, de forma ainda mais explícita, a destituição de legitimidade da relação entre mulheres e futebol profissional:

(2). Sabe o nome disso? F - R - A - G - I - L - I - D - A - D - E, é isso que está por trás desse "hino" que usa frustração e limitação como combustível. Pagode forçado. Letra forçada. Futebol forçado. Protagonismo forçado. Tosco de mais (Comentário 2: disponível em GLOBO ESPORTE, 2019, KESTELMAN, BASTOS, 2019).

Nesse comentário 2, destacamos o uso do termo fragilidade. Embora aparentemente o usuário o esteja aplicando em relação à modalidade futebol feminino, o destaque deliberado expresso em letras maiúsculas e separadas por hífen remete ao mito da fragilidade, à ideia da mulher como o sexo frágil, em oposição ao homem sexo forte. O imaginário histórico das mulheres possuidoras de uma essência fragilizada tem como fundamento aspectos biológicos. Contudo, reverbera para além dessa esfera. Significa, ao mesmo tempo, fraqueza física, mas também ingenuidade emocional e intelectual, delicadeza e passividade que pressupõe uma relação de dominação, normalmente manifesta na submissão ao homem, pai, irmão ou esposo. O mito da fraqueza, de acordo com Teixeira e Caminha (2013), atua como obstáculo para inserção das mulheres no futebol, uma vez que consolidou uma crença de que esforço físico seria inapropriado para uma suposta natureza feminina.

Outro aspecto que chama atenção é o uso reiterado da palavra "forçado". Mais uma vez, o espaço ocupado pela jogadora de futebol mulher está sendo deslegitimado. Ao lançar mão do termo 
Mulheres no futebol: uma análise midiática pela perspectiva dos estudos culturais Andressa Araujo Furquim • Maísa Ferreira • Nara Romero Montenegro • Rubens Antonio Gurgel Vieira

"forçado", o usuário atribui uma representação ligada à artificialidade, à falsidade. Supostamente as mulheres que ultrapassam a barreira do preconceito estariam perfomatizando ${ }^{3}$, atuando, encenando, "forçando", como se houvesse uma maneira natural, essencial e única de ser mulher.

Seguimos nas análises dos comentários:

(3) Futebol feminino não presta para nada, vão formar uma família que é melhor. (4). De 23 convocadas só uma que tem fiIho... se depender das jogadoras a gente entra em extinção... só querem curtir igual jogador... mas criar filho, constituir família... não querem... foge da responsabilidade... só querem viver de gandaia!!!! É claro que elas têm opção de não terem filho..., mas de 23 apenas 1 ter filho... está muito desproporcional!!! Acho que tem que ensinar na base que pode conciliar futebol e família. (Comentários 3 e 4: disponíveis em GLOBO ESPORTE, 2019 KESTELMAN, BASTOS, 2019).

Os comentários acima defendem a premissa de que as mulheres têm como obrigação a criação e manutenção de uma família, nitidamente uma família tradicional: heterossexual, matrimonial e com a concepção de filhos. Tal representação vem da ideia amplamente difundida ao longo dos últimos séculos de que a mulher é o núcleo da reprodução, responsável primordial pela continuação da vida (GOELLNER, 2003). Ao reivindicar que as jogadoras estão fugindo da "responsabilidade" e que "só querem curtir igual jogador", o usuário está assumindo que há um papel a ser cumprido pela mulher e que, nesse caso, é diferente do homem. Mais um mito atribuído às mulheres se expressa: o mito da maternidade.

O quinto comentário adentra na discussão a respeito da sexualidade e orientação sexual das jogadoras:

\footnotetext{
3 Ao considerar a linguagem enquanto criação humana como forma de aumentar a expressão da vida, não podemos deixar de lado sua função ativa na construção do conhecimento e formação subjetiva. O conceito de performatividade transfere a ênfase no ser para a processualidade. Sendo assim, o enunciado com potencial performático se torna necessário para as consequências daquilo que prediz, naturalizando algumas construções culturais. O conceito é muito importante para linguistas e analistas culturais, e neste texto o tomamos principalmente a partir dos escritos de Butler (2003).
} 
(5). "Só uma pergunta: a Cris é normal? Ou é igual a Marta? Gosta de uma manga bem suculenta rsrsrsr. (6) Importa sim a fruta que ela deveria gostar foi a que Deus criou. Vou te dizer mais, nunca ganharão nada!!!" (Comentários 5 e 6: disponíveis em GLOBO ESPORTE, 2019, KESTELMAN, BASTOS, 2019).

Mais uma vez a ideia de uma anormalidade, estranheza e antinatureza compõe o argumento dos usuários, agora para especular a orientação sexual das jogadoras Cristiane e Marta. Através de uma linguagem depreciativa, o comentário 5 levanta a questão se a orientação sexual de Cristine seria a mesma de Marta, no caso homossexual. O comentário 6, dialogando com um possível terceiro interlocutor que parece ter repreendido o primeiro, reafirma o interesse na sexualidade das jogadoras. Manifesta ainda julgamentos de que há uma sexualidade correta, legítima, isto é, "aquela que Deus criou". O usuário utiliza-se de um argumento que tem como base a moral religiosa cristã para argumentar a favor de sua perspectiva heteronormativa, preconceituosa e excludente.

De acordo com Louro (2000), a orientação sexual de cada um não se limita a uma característica pessoal, pois é uma questão político-social que se relaciona com a produção do sujeito pós-moderno. A religião é uma grande fonte formadora de opinião, espaço que dita regras a serem seguidas e, pelo que demonstra, é também um canal de verdade que orienta esse tipo de pensamento.

É possível vislumbrar, portanto, pela análise do circuito da cultura, como a mídia projeta a mulher no futebol. O exemplo que utilizamos aqui aponta como a cultura regulamenta e determina quais representações recebem visibilidade para serem consumidas globalmente, ou seja, seleciona quais discursos, imagens, textos escritos ou músicas são divulgados, operando assim na produção da identidade da mulher, estabelecendo limitações nesta identidade - ora com relação aos aspectos físicos, ora acerca da orientação sexual ou comportamentos sociais.

Em análises mais recentes e mais próximas aos EC, Butler (apud FIRMINO e PORCHAT, 2017) afirma que a discussão entre 
sexo e gênero é longa nas ciências humanas e apresenta limites de possibilidade de conclusão - o que coloca a questão de forma permanente, sempre focalizada em seus aspectos performativos. No entanto, o que nos interessa aqui é o arcabouço teórico de Butler, que fornece como pano de fundo a articulação entre os feminismos e os movimentos sociais.

Butler critica o firmamento da identidade feminina como forma de ativismo, pois isso acaba por produzir a exclusão dos sujeitos que não se enquadram no ser feminino, mas se consideram mulher, dentre outras opções que afastam da normalidade. Sendo assim, os estudos da autora se preocupam em entender de que forma essas identidades são produzidas e quais as relações de poder que as mantêm (FIRMINO; PORCHAT, 2017). Adichie, por sua vez, define o sujeito feminista como "a pessoa que acredita na igualdade social, política e econômica dos sexos" (ADICHIE, 2012, p. 33), demonstrando o caráter ativista do movimento em que uma das premissas é questionar como as mulheres são criadas. Quando as lutas buscam equidade e igualdade, não se pode estabelecer uma competição para as mulheres atingirem o padrão "homem". Por conseguinte, o caminho é a existência plena dos corpos e uma das maneiras é a influência da mídia. A identificação é influenciada pelo acesso de representatividade nas mídias, que é diferente entre os gêneros masculinos e femininos. Segundo a escritora nigeriana:

Nós ensinamos meninas a se encolher, para se tornar menor. Nós dizemos para meninas: "você pode ter ambição, mas não muito, você deve procurar ser bem-sucedida, mas não muito bem-sucedida, caso contrário, você ameaçará o homem". [...] porque eu sou mulher e esperam que eu aspire a casamento, esperam que eu faça minhas escolhas de vida sempre tendo em mente que o casamento é o mais importante. Agora o casamento pode ser uma fonte de alegria, amor e apoio mútuo, mas por que ensinamos meninas a aspirar ao casamento e nós não ensinamos meninos o mesmo? [...] nós criamos garotas umas 
para as outras como concorrentes, não para empregos ou para realizações, o que eu acho que pode ser uma coisa boa, mas pela atenção dos homens. Nós ensinamos meninas que elas não podem ser seres sexuais na maneira que os meninos são. [...] (ADICHIE, 2012, p. 33-35).

Dentro dessa lógica é que este trabalho se apresenta como um manifesto de resistência, um espaço de questionamento das situações sintomáticas e preconceitos sofridos pela categoria muIheres no esporte.

\section{Considerações finais}

Como vimos, uma forma de governar a cultura é entender seu circuito, os canais de informação que determinam quais representações recebem visibilidade para serem consumidos globalmente, ou seja, como se dá o mecanismo que seleciona discursos (imagens, textos escritos ou músicas) a serem divulgados, operando, assim, a produção de identidades e construindo fronteiras baseadas em aspectos físicos, orientação sexual e comportamentos sociais - algo que recusamos veementemente.

Outro ponto importante, não sendo os indivíduos seres autônomos governados pela razão, mas subjetivados pela cultura de inserção, as memórias destacadas nos comentários formam certa identidade nacional, uma estrutura estatal defendida por leis e regulamentos que apresenta arcaísmos insustentáveis. O esporte moderno, ainda que apresente aspectos que extrapolam a questão identitária, não é parte dos processos sociais que reproduzem preconceitos, como pode ser observado no caso do futebol feminino brasileiro. Assim, o futebol, como uma modalidade com prática de maioria de homens, tanto no contexto do alto rendimento quanto no meio escolar ou outros ambientes, compõe um espaço ainda inóspito para boa parte das mulheres. Ainda que não neguemos os avanços, muito há de ser feito. 
Conclui-se, nesta investigação, que toda sociedade colabora na construção de o que é ser mulher dentro da cultura. Existe um predomínio de preconceitos sofridos pelas mulheres, praticado pelas pessoas que acessam e comentam o canal de informação, que além de colaborar para o pouco espaço das mulheres no esporte, refletem a influência de certas representações.

\section{Referências}

ADICHIE, Chimamanda Ngozi. Sejamos todos feministas. Tradução: Christina Baum. 1. ed. São Paulo: Companhia das Letras, 2012. $64 \mathrm{p}$.

BRACHT, Valter. Sociologia Crítica do Esporte: Uma Introdução. 3. ed. Unijuí: UNIJUÍ, 2005. 136 p.

BUTLER, Judith. Problemas de Gênero. Rio de Janeiro: Civilização Brasileira, 2003.

COIRO-MORAES, A. L. A análise cultural: um método de procedimentos em pesquisas. Questões Transversais - Revista de Epistemologias da Comunicação, v. 4, p. 28-36, 2016.

ESCOSTEGUY, Ana Carolina. Uma Introdução aos Estudos Culturais. Revista FAMECOS, Porto Alegre, n. 9, p. 87-97, dez. 1998.

FERREIRA, Mario Jordão Pessoa; BEZERRA, José Airton Xavier; SILVA, Kaethy Vasconcelos; CERANI, Rodrigo Benevides; LOPES, Diego Trindade. Preconceito No Futebol Feminino No Brasil: Uma Revisão Narrativa. Diálogos em Saúde, Paraíba, v. 1, n. 2, p. 112128, jul./dez. 2018.

FIRMINO, Flávio Henrique. PORCHAT, Patrícia. Feminismo, identidade e gênero em Judith Butler: apontamentos a partir de "problemas de gênero". Doxa: Rev. Bras. Psicol. Educ., Araraquara, v.19, n.1, p. 51-61, jan./ jun. 2017.

GOELLNER, Silvana Vilodre. Mulheres e futebol no Brasil: entre sombras e visibilidades. Revista Brasileira de Educação Física e Esporte, Rio Grande do Sul, v. 19, n. 2, p. 143-151, 2005. 
GOELLNER, Silvana Vilodre. Bela, maternal e feminina: imagens da mulher na revista Educação Physica. Ijuí, RS: Editora Unijuí, 2003.

HALL, S. A centralidade da cultura: notas sobre as revoluções culturais do nosso tempo. Educação \& Realidade, Porto Alegre, v. 22, n. 2, p. 15-46, jul./dez. 1997.

HALL, Stuart. A identidade cultural na pós-modernidade. Tradução: Tomaz Tadeu da Silva e Guacira Lopez Louro. 11. ed. Rio de Janeiro: DP\&A, 2006.

HALL, Stuart. Cultura e Representação. In: ITUASSU, Arthur (Org.). Tradução: Daniel Miranda e William Oliveira. Rio de Janeiro: Ed. PUC-Rio, 2016.

HALL, Stuart. Da Diáspora: Identidades e Mediações Culturais. Belo Horizonte: Editora UFMG; Brasília: Representação da UNESCO no Brasil, 2003. 434 p.

KESTELMAN, Amanda; BASTOS, Denise Thomaz. "Qual é, qual é... futebol não é pra mulher?": conheça a história por trás do hino da Seleção na Copa. França: 2019. Disponível em: https://globoesporte.globo.com/futebol/copa-do-mundo-feminina/noticia/ qual-e-qual-e-futebol-nao-e-pra-mulher-conheca-a-historia-por-tras-do-hino-da-selecao-na-copa.ghtml. Acesso em: 15 mai. 2020.

LOURO, Guacira Lopes. (Org.). O corpo educado: pedagogias da sexualidade. Tradução: Tomaz Tadeu da Silva. 2 ed. Belo Horizonte: Autêntica, p. 4-24. 2000.

MORAES, C. BONFIM, A. F. Mulher no Futebol: no campo e nas arquibancadas. In: Daniela Stefano; Maria Luisa Mendonça. (Org.). Direitos Humanos no Brasil 2016 - Relatório da Rede de Justiça e Direitos Humanos. 1 ed. São Paulo: Outras Expressões, 2016, v. 1, p. 177-187.

ROCHA, Simone Maria. Os Estudos Culturais e a Análise Cultural da Televisão: Considerações Teórico-Metodológicas. Animus Revista Interamericana de Comunicação Midiática, Santa Maria, v. 10, n. 19, sem. 2011. 20 p. Disponível em: http://dx.doi. org/10.5902/217549773000. Acesso em: 10 abr. 2020. 
Mulheres no futebol: uma análise midiática pela perspectiva dos estudos culturais

Andressa Araujo Furquim • Maísa Ferreira • Nara Romero Montenegro • Rubens Antonio Gurgel Vieira

STIGGER, Marcos Paulo. Educação Física, Esporte e Diversidade. 1. ed. Campinas: Autores Associados. 2005. 134 p.

TEIXEIRA, Fábio Luís Santos; CAMINHA, I. O. Preconceito no futebol feminino brasileiro: uma revisão sistemática. Movimento (Porto Alegre. Online), v. 19, p. 265-287, 2013.

WOODWARD, K. Identidade e diferença: uma introdução teórica e conceitual. In: SILVA, Tomaz Tadeu da. (Org.). Identidade e Diferença: A Perspectiva dos Estudos Culturais. Petrópolis: Vozes, p. 7-72. 2008.

\section{Publisher}

Universidade Federal de Goiás. Faculdade de Educação Física e Dança. Publicação no Portal de Periódicos UFG. As ideias expressadas neste artigo são de responsabilidade de seus autores, não representando, necessariamente, a opinião dos editores ou da universidade. 